\title{
A MÃE E O PROCESSO ALIMENTAR DA CRIANÇA
}

\section{ARTIGO ORIGINAL}

PALLADINO, Ruth Ramalho Ruivo"1, SOUZA, Luiz Augusto de Paula², CARMO, Roseli Cristina Campos do ${ }^{3}$, PEREIRA, Daiane Regina ${ }^{4}$, CUNHA, Maria Claudia ${ }^{5}$

PALLADINO, Ruth Ramalho Ruivo. Et al. A mãe e o processo alimentar da criança. Revista Científica Multidisciplinar Núcleo do Conhecimento. Ano. 07, Ed. 02, Vol. 02, pp. 05-34. Fevereiro de 2022. ISSN: 2448-0959, Link de acesso: https://www.nucleodoconhecimento.com.br/saude/processo-alimentar, DOI: 10.32749/nucleodoconhecimento.com.br/saude/processo-alimentar

\section{RESUMO}

O humano não consome apenas o alimento que encontra na natureza, ele o prepara e/ou produz: a comida é também cultura e tecnologia. Mais ainda, o humano escolhe o que ingerir e a ingestão é (com)partilhada, o que denota os valores simbólicos e sociais de que a comida se reveste. Por isso, a fome ou a saciedade não são resultantes apenas do desequilíbrio ou equilíbrio proteico-calórico e de hidratação, mas também de memórias: imagens, cheiros, sons, histórias e desejos. A alimentação é, então, função orgânica que será sobredeterminada simbolicamente, se entrelaçará com um outro funcionamento humano, a linguagem, numa operação iniciada na interação mãe-bebê e encenada a partir da amamentação. Este artigo de pesquisa, a partir de uma casuística de 30 mães com bebês recém-nascidos, analisa a construção da posição materna em cenas alimentares com seus bebês, delineando suas características interacionais, suas consequências para a relação mãe-bebê, para o desenvolvimento da criança e para subjetividade dessas mulheres, inclusive em função de orientações técnicas, entre outras, de pediatras e de fonoaudiólogos sobre

\footnotetext{
${ }^{1}$ Doutorado em Psicologia (Psicologia Clínica). ORCID: 0000-0001-8466-838X

2 Doutorado em Psicologia. ORCID: 0000-0003-4968-9753

${ }^{3}$ Mestrado em fonoaudiologia. ORCID: 0000-0002-1768-0423

${ }^{4}$ Mestrado em andamento em Fonoaudiologia. ORCID: 0000-0001-7773-6583

${ }^{5}$ Doutorado em Psicologia. ORCID: 0000-0003-3198-6995
} 
a alimentação de seus filhos. Os dados mostram que a amamentação é, na grande maioria dos casos, um desejo das mulheres, o que põe em realce o vigor e o valor da posição de alimentadora da mãe e, mais ainda, dela ser fonte do alimento do bebê. Observou-se, por fim, que a orientação especializada para as mulheres (do estudo) sobre a amamentação é feita, sobretudo, em período pós-natal, privilegiando sua importância quanto aos aspectos nutricionais da criança. Contudo, foi possível verificar, em muitas respostas das mães, que a amamentação constitui, principalmente, momento de prazer relacional, encenado pela intensa busca de interação com a criança, que reage com mudanças visíveis de comportamento corporal e porque olha para a mãe como resposta às suas palavras e carinhos, o que faz com que ela já reconheça aí intenção e comunicação.

Palavras-chave: Relação mãe-bebê, Amamentação, Alimentação, Linguagem.

\section{INTRODUÇÃO}

A possibilidade de um entrelaçamento entre o que se dá a ver na prática cotidiana e certas proposições teóricas é uma questão que, repetidamente, se impõe aos clínicos. Tal entrelaçamento, por vezes, gera estranhamento e fica paralisado, jacente num duplo silêncio, do inédito da clínica e da ineficácia das explicações (FOUCAULT, 1994). Foi isso o que se passou com a relação entre linguagem e alimentação, ela ficou algum tempo num duplo silêncio.

A prática clínica fonoaudiológica trouxe à cena uma observação que ganhou contorno cada vez mais definido: as mães das crianças em avaliação de linguagem, nas entrevistas ou mesmo nas conversas informais no decorrer desse processo, além de se queixarem sobre dificuldades na linguagem, insistiam em trazer considerações sobre a alimentação de seus filhos (PALLADINO; SOUZA e CUNHA, 2004). Durante o processo diagnóstico, cedo ou tarde, elas relatavam algumas dificuldades ou mesmo idiossincrasias alimentares de seus filhos que ficavam, assim, coladas às próprias queixas sobre a linguagem. 
Entretanto, um fato se tornou instigante: não havia, na maioria das crianças, alterações em motricidade orofacial e/ou disfunção na deglutição, que pudessem justificar a concomitância das queixas e, talvez, até mesmo explicar certos desvios de fala (GIACCHINI et al., 2013). Por que, então, essas duas queixas entrelaçavam-se nas palavras maternas?

Essa indagação inspirou um estudo visando identificar uma provável coocorrência dos sintomas de linguagem e de alimentação ou se, diferentemente, seria apenas uma coincidência. Os resultados dessa investigação consolidaram a ideia de coocorrência (PALLADINO; SOUZA e CUNHA, 2004). Tal estudo pesquisou 35 crianças com diagnósticos completos de atraso de linguagem. Os casos foram divididos por faixa etária em 03 grupos ( 10 crianças de até 03 anos; 20 crianças de 03 a 05 anos; 05 crianças de 05 a 07 anos), nos quais levantou-se queixas maternas sobre dificuldades de linguagem e dificuldades alimentares, realizados em qualquer período do processo de avaliação de forma induzida ou espontânea. A partir daí, por meio de análise estatística implicativa com o software CHIC (Classificação Hierárquica, Implicativa e Coercitiva), a coocorrência dos problemas de linguagem e alimentares evidenciou-se em $100 \%$ dos casos.

Outros estudos foram empreendidos e sempre reafirmaram a hipótese de existência de coocorrência entre problemas de linguagem e alimentares em crianças (PALLADINO; CUNHA e SOUZA, 2007; MACHADO, 2007; PEDROBOM et al., 2009; PEDROBOM, 2012), distanciando a discussão da ideia de coincidência nosológica, conduzindo-a à suposição de uma relação constitutiva entre essas duas funções fundamentais: comer e falar.

Esses estudos sobre tal coocorrência apontaram, entre outros aspectos, a natureza simbólica da alimentação. Geralmente, as alterações de alimentação são tratadas pela fonoaudiologia, com alocação preferencial no campo da motricidade orofacial, sob perspectivas fortemente biológicas, que admitem questões de outras ordens (psíquica e social) apenas tangencialmente (FERRIOLLI, 2010; REGA, 2012; SILVA GOMES et al., 2016). Nesse sentido, é importante buscar outros aportes teóricos para entender, inicialmente, porque queixas sobre a alimentação surgem na clínica 
fonoaudiológica também fora das alterações e/ou problemas na motricidade orofacial. Elas surgem porque a alimentação seria, sobretudo, uma função simbolicamente constituída? A resposta afirmativa à indagação é a hipótese a ser aqui trabalhada.

\section{A ALIMENTAÇÃO COMO FUNÇÃO SIMBÓLICA}

As ciências humanas perfilam a alimentação e a linguagem, estruturando-as num laço funcional de natureza simbólica, instituindo-as como funções fundamentais, protagonistas da humanização do filhote humano (LÉVI-STRAUSS, 2004; MONTANARI e FLANDRIN, 2008), algo que teria se dado evolutivamente, quando a alimentação ganhou também "importância simbólica" (SOUZA LIMA et al., 2015). A antropologia, com estudos sobre tribos indígenas, traz explicações interessantes: formulações míticas que explicam processos humanizadores e civilizatórios, nos quais a alimentação tem papel preponderante. Veja-se um exemplo.

O relato de alguns mitos e rituais da tribo Kikrin, etnia indígena da língua Jê, do Pará/Brasil, revela que o ser humano é constituído pela união de duas partes: uma formação corpórea orgânica e o karon, a alma ou o duplo. A primeira, o corpo, é o território que dá sustentação e morada para a segunda, a alma. Os cuidados oferecidos à criança devem ser extremos, uma vez que precisam, simultaneamente, garantir a saúde do corpo e vigiar os passeios da alma. Sim, porque a alma para os Kikrin compõe-se num entra-e-sai do corpo até que se aquiete. Para o corpo não adoecer e a alma não se perder, ou seja, para ultrapassar a vulnerabilidade radical da criança pequena, cuidados são fundamentais, sobretudo na alimentação e em sua conjunção com o sono infantil (COHN, 2005; PALLADINO et al., 2021). O ritual de amamentação seguido do adormecimento ganha revelo nos primórdios da vida da criança com sua mãe ou cuidador principal, por meio desse rito, que se repete dia após dia, a mãe vigia e cuida para que a criança se humanize, torne-se um semelhante.

Historiadores, por sua vez, contam como o alimento entrou na cena da composição humana: sua existência na linguagem, na conformação do próprio corpo, na produção cultural e tecnológica. Em outros termos, "comida comunica cultura, significados e 
valores" (ROCHA, 2018, p. 66), tem "valor psicológico independente do valimento fisiológico" (CASCUDO, 1963 apud ROCHA, 2018, p. 66).

O humano não consome apenas o alimento que encontra na natureza, ele o prepara e/ou produz e, assim, a comida é também cultura e tecnologia. Mais ainda, o humano escolhe o que ingerir e a ingestão é (com)partilhada, o que denota os valores simbólicos e sociais de que a comida se reveste. Por isso, a fome ou à saciedade não são mais resultantes apenas do desequilíbrio ou equilíbrio proteico-calórico e de hidratação, mas também de memórias: imagens, cheiros, sons, histórias, desejos.... Enfim, a alimentação é um elemento decisivo da identidade humana e se apresenta como um dos meios mais eficazes para comunicá-la (MONTANARI e FLANDRIN, 2008).

Afirmar que a alimentação é uma função construída, de valor simbólico, implica acatar a ideia de que a relação entre o humano e a natureza não é direta, ela é mediada pela linguagem na relação com outro(s) humano(s). Assim, comer é uma cena intersubjetiva por excelência. Ademais, em razão do fato de que os membros da espécie se alimentam, privilegiadamente, de modo compartilhado, na comensalidade, esta cena tem a qualidade de ser social (MOREIRA, 2010). Aqui também fica evidente que a presença do outro na cena alimentar é condição fundamental.

Outro campo do conhecimento, também interessado nos fatos humanos, as ciências médicas, por tradição, ofereceram à linguagem e à alimentação explicações de cunho predominantemente organicista. Tal perspectiva acabou, eventualmente, reduzindo a possibilidade de relação implicativa entre as funções.

No campo da saúde, em função da ascendência das ciências médicas, aos poucos, algumas tentativas de aproximação entre alimentação e linguagem foram se dando, sobretudo pelas disciplinas que já podiam supor o sujeito humano para além do seu organismo. A psicanálise, uma delas, reconheceu o caráter simbólico de ambas as funções, sugerindo, inclusive, uma relação de implicação entre alimentação e linguagem. Tal entrelaçamento passou a compor um espaço privilegiado, a ponto de se destacar na compreensão de sintomas indiciários de transtornos psíquicos. Freud 
(1905/1996, p. 210) afirmou que "para a criança, a amamentação no seio materno torna-se modelar para todos os relacionamentos amorosos. O encontro do objeto é, na verdade, um reencontro".

Há muito, a psicanálise de crianças aponta para o papel fundamental que a alimentação desempenha na configuração subjetiva e, sobretudo, escancara a relação em seus eventuais descaminhos: a delicada relação entre mãe e bebê na amamentação, tem na dolorida situação dos bebês com alimentação alternativa precoce um problema digno de nota, uma vez que "descarta o tempo rico de trocas da alimentação" (QUINIOU, 1999, p. 56). Aliás, pode ter consequências também problemáticas o "ataque direto ao distúrbio alimentar pela via exclusiva de terapêuticas dirigidas à alimentação (...) no sentido de estimular as disposições psicopatológicas da criança” (KREISLER, 2003, p. 118).

"Na comida está em jogo muito mais que a fome" (LAJONQUIĖRE, 2010, p.151), o que encaminha a compreensão para o fato de que a significativa expressão sintomática dos "distúrbios alimentares e os vômitos associados a quadros fóbicos ou anoréxicos e as febrículas recorrentes sem explicação (...) são demonstrativos de até que ponto as determinações simbólicas capturam o corpo da criança (...)" (JERUSALINSKY, 2004, p. 24). Sintomas aparentemente funcionais, segundo Kupfer (2000, p. 89), explicam-se pelo fato de que

a boca não erotizada, não recortada pelo trabalho materno de fazer nascer a pulsão oral, nisso que é pura carne, pura necessidade, estará sempre semiaberta, hipotônica, sem tônus; a criança exibirá uma baba constante, a deslizar por entre seus lábios moles.

Mas o campo médico, em alguma medida, permaneceu mais algum tempo relativamente refratário a tal possibilidade de abordar a questão. No entanto, a partir da década de 1980, nos Estados Unidos, questões culturais e psicológicas da alimentação passam a ser pesquisadas na medicina, direcionando providências tanto nas ações diagnósticas quanto nas terapêuticas.

$\mathrm{Na}$ endocrinologia pediátrica, por exemplo, houve estudos argumentando que os transtornos alimentares indiciam tais aspectos, uma vez que sua origem se atrela ao 
momento inicial da vida do bebê, sustentado essencialmente pela interação que se estabelece entre ele e sua mãe. Essa ideia reverbera na conduta clínica de profissionais médicos, que passam a basear o diagnóstico do transtorno alimentar não apenas nos chamados "exames objetivos", mas também na análise da cena alimentar entre mãe e criança, além da pesquisa sobre esta interação (CHATOOR et al., 1998).

A psicanálise oferece contribuição importante para tais estudos médicos, na medida em que apresenta a possibilidade de distinção entre dois transtornos: o alimentar e o de alimentação, sendo o primeiro constituído por "perturbações no ato de comer" e o segundo por "perturbações no ato de dar de comer" (GUSMÃO, 2002, p. 46), ou seja, aponta-se a dupla fonte do transtorno, baseada na ideia de que a relação entre alimentador e alimentado é base do processo. Enfim, a psicanálise, ou disciplinas por ela inspiradas, também trazem à discussão a presença da mãe, como condicionante ao desenvolvimento dessa contingência fundamental de natureza interacional.

Apesar de tais esforços, não é incomum observar, na prática da pediatria, a reiteração da percepção de que há dois tipos de transtornos, os de origem orgânica e os que são determinados também por fatores psicológicos, o que não a aproxima plenamente da ideia de que a alimentação, nos humanos, tem natureza simbólica. Nessa medida, eventualmente, há dificuldades da pediatria em auxiliar a fonoaudiologia na identificação da coocorrência dos problemas de alimentação e de linguagem em crianças.

Mais recentemente, pesquisas têm reforçado a ideia de que ambas as funções fundamentais, comer e falar, têm caráter simbólico e, mais ainda, postulam que a primeira cena de linguagem entre o bebê e sua mãe é a alimentação, especificamente a amamentação (MARIOTTO, 2003; THIBAULT, 2006; PALLADINO; CUNHA e SOUZA, 2007; PALLADINO et al., 2021).

Em dezembro de 2004, a Revista da Sociedade Francesa de Fonoaudiologia publica um número, com diversos artigos, dirigido a um só tema: a construção pela criança das oralidades, alimentar e verbal. São artigos diversos, de profissionais de áreas igualmente distintas, que mostram como o bebê vai construindo sua subjetividade. $O$ 
foco das teorizações é exatamente a construção simbólica das oralidades, alimentar e verbal, no bojo da interação entre o bebê e sua mãe. Nessas teorizações, os estudiosos postulam que as oralidades são um efeito de construção, não são "naturais", se dão num sistema de implicação orgânico/simbólico e estão na base de todo o desenvolvimento. Em suma, as oralidades alimentar e verbal são acontecimentos simbólicos que se entrelaçam desde sempre: "a boca é a encruzilhada anatômica do verbo e do alimento" (THIBAULT, 2006, p. 122.), daí os transtornos serem faces da mesma moeda.

É importante atentar para o fato de que a conduta materna é, nos primórdios da relação com o bebê, determinante, sendo que

Na maioria dos casos, a oferta do seio será marcada, na sua forma e na sua temporalidade, pelos hábitos culturais que determinam o comportamento da amamentação que se faz em função do desejo materno em relação à criança, da qualidade desse desejo tal qual ele se manifesta, no sentimento que o eu da mãe tem pelo recém-nascido, do que o discurso cultural propõe como bom modelo da função materna. (AUGALIGNER, 1975/1979, p. 39)

Em suma, a alimentação é função orgânica que será, no humano, sobredeterminada simbolicamente, se entrelaçará com uma outra, a linguagem, numa operação iniciada na interação mãe-bebê, encenada a partir da amamentação. Neste sentido, tentar conhecer a construção da posição materna em cenas alimentares, importa em discussões sobre a cena interacional e suas consequências.

\section{A MÃE E O PROCESSO ALIMENTAR DA CRIANÇA}

Há muitos estudos sobre a relação da mulher com a comida e o cozinhar, na figura da responsável pela alimentação e, assim, pela nutrição e sobrevivência da família (GUEDES e DAROS, 2009). Apesar desse protagonismo, à mulher não ficou reservado nenhum privilégio: a sua ração na distribuição da comida, mesmo em tempos de maior fartura a partir do século XIX, sempre foi menor ou, então, foi especialmente definida, visando prolongar sua capacidade reprodutiva, outra função pilar na formação dos grupos sociais (BAIÃO e DESLANDES, 2006). Em outras palavras, a alimentação, de certa forma, dá prazer e valor à mulher na sua posição de alimentadora. Uma posição revigorante, mas vale atentar para o fato dela não obter a 
mesma possibilidade narcísica na outra posição no processo, a de alimentada, o que, certamente, faz marca psíquica e na estrutura social.

O valor de alimentadora revela-se exponencialmente na maternidade, quando a criança entra na equação. Uma cena ambígua, psiquicamente fantasiada pela mulher e culturalmente (im)posta (FREIRE, 2008; GUEDES e DAROS, 2009), uma construção que nem sempre coincide.

A gestante é orientada a consumir alimentos específicos, em tipos e quantidades, para dar conta da nutrição do bebê, evitando, assim, provocar problemas embrionários, de desenvolvimento. Vale observar que as orientações de obstetras circulam, frequentemente, no espaço nutricional com vistas ao bebê, inclusive impedindo ou receitando o consumo limitado de alimentos pela gestante, para não haver problemas nem no desenvolvimento do bebê nem no parto, como, por exemplo, a obesidade (SEABRA et al., 2011; GAMA et al., 2014). O prazer e valor da mulher em sua posição de alimentadora revela-se na possibilidade de garantir saúde ao bebê, ainda que o regime alimentar assumido não privilegie exatamente suas preferências ou idiossincrasias do momento. A responsabilidade surge outra vez como vetor de escolhas ou possibilidades socialmente engendradas.

Perfilada à orientação nutricional, frequentemente, está uma outra, a que estimula o apego da mãe ao seu bebê, ainda em gestação, com vistas aos laços afetivos futuros da criança (ALVARENGA et al., 2015). A cultura insiste no sentimento de alegria que deve inundar a gestante, uma das mais significativas fontes de estímulo para o apego.

Perto do parto, as orientações começam a ir rumo à questão da amamentação, posição máxima da mulher como alimentadora. Consuma-se um ato absolutamente inédito, que inscreve a mulher numa posição de marcada tonalidade narcísica, ainda que o entorno the imponha e cobre certos cuidados para garantir "um bom leite": ela é a fonte do alimento do bebê. Isso lhe dá um prazer imenso, que não perde em significado mesmo com as imposições culturais que determinam seu cardápio e comportamento. Nesta cena, a mulher ganha revelo social e importância no grupo familiar (CUNHA e SIQUEIRA, 2016). 
Note-se, contudo, que percepções, sensações, pretensões, desejos e sentimentos maternos não ganham tanta luminosidade nas orientações técnicas e, assim, não determinam nem sua estrutura nem seus conteúdos, apesar de determinarem, nesta vez, o desempenho da mãe na posição de alimentadora (PRADO et al., 2017). E determinam de modo quase decisivo, uma vez que apresentam modelos de comportamento no ato da mamada, sobretudo no ensinamento das atitudes adequadas para a pega do seio que, se não for exitosa, supostamente será por motivos principalmente ligados à mãe (BARBOSA et al., 2017).

Importa notar que a "maternidade" é vista como algo natural, que se dá de modo homogêneo com todas as mulheres, daí as orientações formuladas à revelia da singularidade, considerações que são bem tratadas em um antigo e tradicional estudo de Grisci (1995): "Mulher-mãe".

Além de todas essas questões, vale observar que a mãe, na posição de "amamentadora", também protagoniza uma outra função, a de criar uma interação com seu bebê, um laço que igualmente vai propiciar a constituição subjetiva daquela criança (CRESTANI et al., 2012). Trata-se de interação que já passou por diferentes formulações no processo de apego instaurado ainda na gestação. Essa interação será representada sobretudo na linguagem: olhar para o bebê, cantar para ele, falar com ele, acariciá-lo... Olhar, cantar, falar, acariciar, interagir afetivamente com a criança são efeitos das contingências socioculturais, sustentadas nas representações sociais já citadas, e psíquicas, representadas nas fantasias, desejos, possibilidades e necessidades da mãe; aspectos que não ganham o devido realce nas discussões sobre a estrutura e o funcionamento dessa relação intersubjetiva tão precoce para o bebê, e que tem uma potência incomparável.

O desmame, acontecimento revestido pela cultura, com a ideia de ser algo "natural", encena, mais uma vez, a tensão da mãe na posição de alimentadora, agora com a responsabilidade de fazer a primeira transição alimentar de modo efetivo. Toda orientação reforça o cuidado em relação ao bebê, para que ele possa seguir bem em seu desenvolvimento, sobretudo bem nutrido e aberto às variações de alimentos, inclusive apontando para a decisão da transição como opção incomparável para o 
amadurecimento não apenas orgânico, mas também psicológico da criança. Contudo, avaliar a disponibilidade materna em relação a essa ruptura não é questão frequente, nem dos teóricos, nem dos clínicos, apesar dela fazer marca nesse processo (FERRARI et al., 2017).

A continuidade do processo alimentar também constitui conteúdo das orientações médicas, odontológicas e fonoaudiológicas, que visam, principal e novamente, a maturação e o desenvolvimento adequado da nutrição, dos dentes e da fala. A repercussão desse processo nas considerações maternas, outra vez, não é destacada nas discussões, apesar de ser atribuída à mãe a responsabilidade da seleção dos alimentos, do preparo e da oferta; responsabilidade que cruza com suas preferências, saberes, possibilidades e disponibilidade. As pesquisas mostram que a dinâmica estabelecida na díade mãe-bebê, da gestação às transições alimentares, pode definir um desenvolvimento exitoso ou, então, dificuldades para ambos (ÁVILA et al., 2008)

Esse cenário emoldura a participação da mãe no desenvolvimento infantil, especialmente no que concerne à sua alimentação, participação ditada principalmente por sentidos externos, sociais e culturais, que palpitam no entorno da figura da mãe (MARTINS, 2008).

Em suma, a alimentação infantil surge como espaço fértil para a compreensão do desenvolvimento das interações mãe-bebê, no desenvolvimento do processo alimentar da criança, da amamentação às refeições familiares, tanto no que se refere às ações e reações da criança, quanto nas ações, percepções e sentimentos da mãe. Descrever e tentar entender a interação que sustenta a díade é importante para qualquer decisão em termos de avaliação e tratamento de problemas no desenvolvimento da criança. Amamentar, acalentar e fazer adormecer o bebê exibe, claramente, o entrelaçamento das funções, o que torna mais fácil entender por que sintomas relativos à alimentação e à linguagem sempre comparecerem nas descrições sobre os transtornos do desenvolvimento infantil (JERUSALINSKY, 2004).

Estudos que investiguem esses processos são importantes, destacando-se os que privilegiam a perspectiva materna sobre os processos operados no interior da díade, 
uma vez que para a mulher a função materna não é natural, mas, sim, efeito de condições somáticas, psíquicas e culturais. Enfim, interessa escutar a palavra da mãe em relação à construção das cenas alimentares e isto é, exatamente, o objetivo deste estudo: descrever percepções, sensações e sentimentos maternos da/na interação mãe-criança no processo alimentar.

\section{MÉTODO}

Pesquisa de natureza qualitativa, delineada como estudo de caso, submetida e aprovada por Comitê de Ética em Pesquisa, processo 69035817.0.0000.5482

Casuística: 30 mães de crianças de 03 a 10 anos de idade.

Critério de seleção: mães de crianças na faixa etária de 03 a 10 anos que aceitaram participar do estudo.

Local: escola de uma cidade do estado de São Paulo.

\section{PROCEDIMENTOS}

\section{Etapa 1: Elaboração de instrumento}

O questionário "Mães e Amamentação" foi elaborado a partir de informações oferecidas por estudos de campo, uma vez que não foi encontrado outro instrumento com esta estrutura e com o objetivo similar ao desta pesquisa.

O questionário é composto por 20 perguntas $(P), 12$ do tipo sim/não e 08 com opções, com 06 desdobradas (P1.1 e P1.2; P2.1 e P2.2; P4.1 e P4.2; P7.1 e P7.2; P8.1 e P8.2; P10.1 e P10.2), visando coletar dados sobre amamentação, desmame e transição alimentar. O questionário foi organizado em quatro categorias, a saber:

- Categoria 1 - Antes da Amamentação: expectativa materna sobre a amamentação; 
- Categoria 2 - Durante a Amamentação: processos, sensações maternas e interação com bebê;

- Categoria 3 - Desmame: processo sobre desmame e apoio/orientação profissional;

- Categoria 4 - Transições Alimentar: percepções, sensações e sentimentos maternos no período de transição: procedimentos escolhidos de alimentação e ações maternas na troca de alimentos; interpretação da mãe sobre reações da criança frente às novidades; sua participação na construção do paladar e respeito às preferências infantis; a introdução da criança em refeições familiares.

Etapa 2 - Aplicação do questionário Mães e Amamentação

O questionário foi apresentado para as mães participantes da pesquisa e, posteriormente, respondido conforme orientações de preenchimento. O questionário foi aplicado presencialmente com a marcação imediata da resposta em cada questão.

Etapa 3 - Critérios de análise dos resultados

Os dados do questionário foram registrados em planilha e submetidos a análise estatística descritiva, na qual foram construídas tabelas de frequências (absolutas e relativas) e porcentagens, medidas de tendência central (média e mediana) e dispersão (desvio-padrão, mínimo e máximo).

\section{RESULTADOS}

Representações gráficas referente ao Bloco 1 do instrumento "Antes da amamentação". 
Gráfico 1. P.1.1 Você pretendia amamentar?

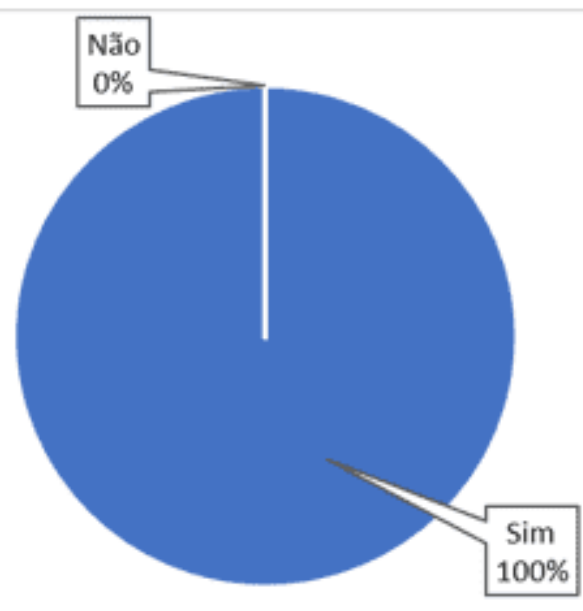

Fonte: autores.

Gráfico 2.P 1.2. Por quê?

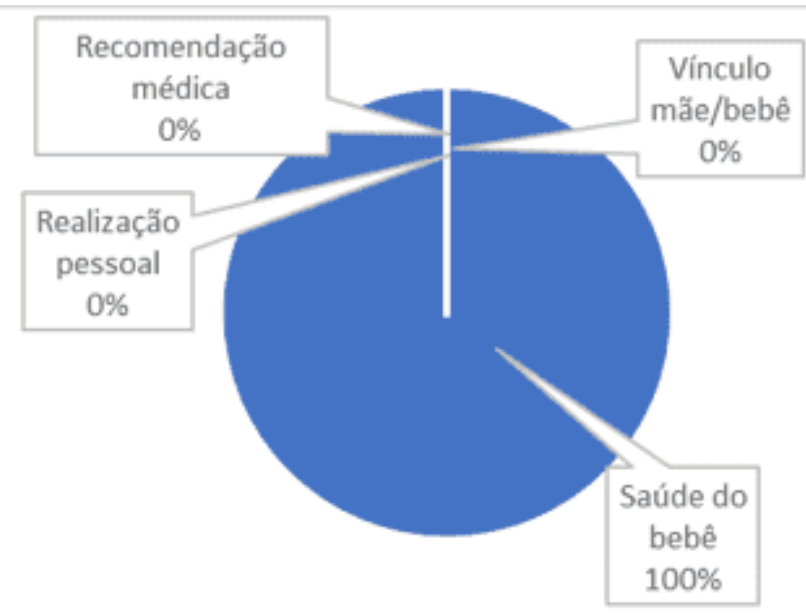

Fonte: autores.

RC: 106346

Disponível em: https://www.nucleodoconhecimento.com.br/saude/processo-alimentar 
Gráfico 3. P2.1. Você recebeu orientações sobre amamentação?

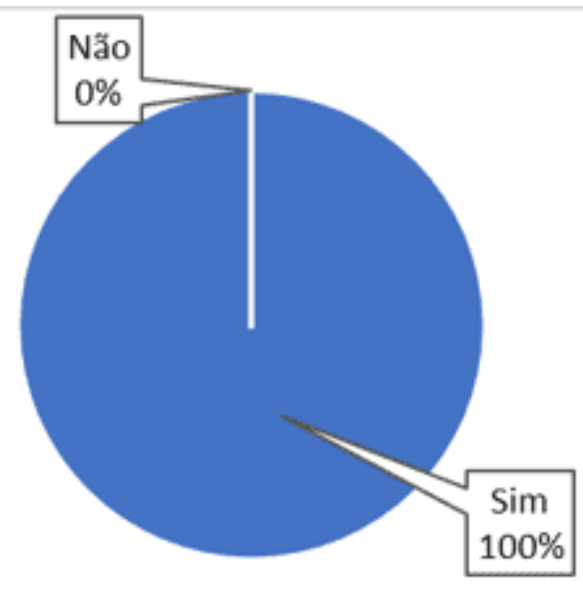

Fonte: autores.

Gráfico 4. P2.2. Qual profissional orientou você sobre amamentação?

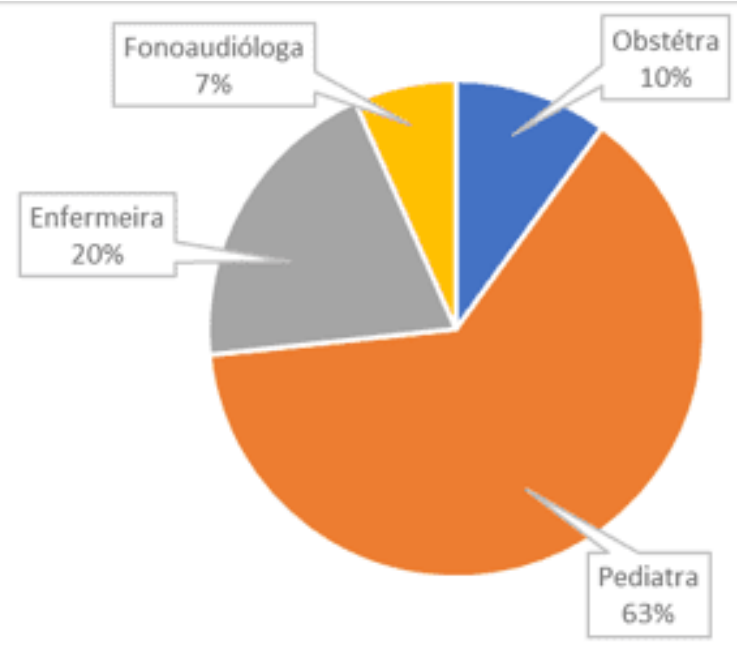

Fonte: autores.

RC: 106346

Disponível em: https://www.nucleodoconhecimento.com.br/saude/processo-alimentar 
Gráfico 5. P 3. Qual foi a orientação?

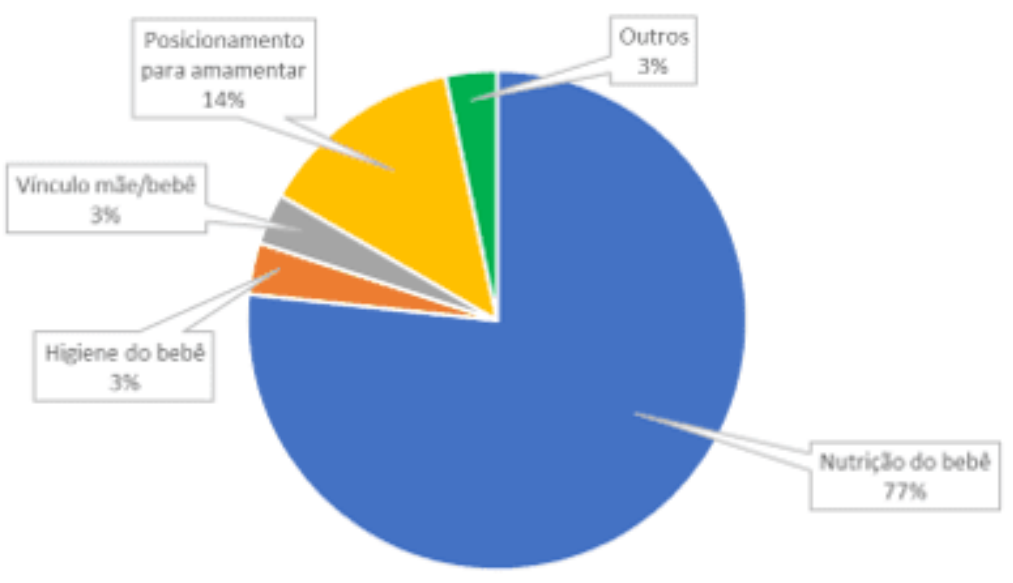

Fonte: autores.

Representações gráficas referentes ao Bloco 2 "Na amamentação".

Gráfico 6. P 4.1. Você amamentou o seu bebê desde o nascimento?

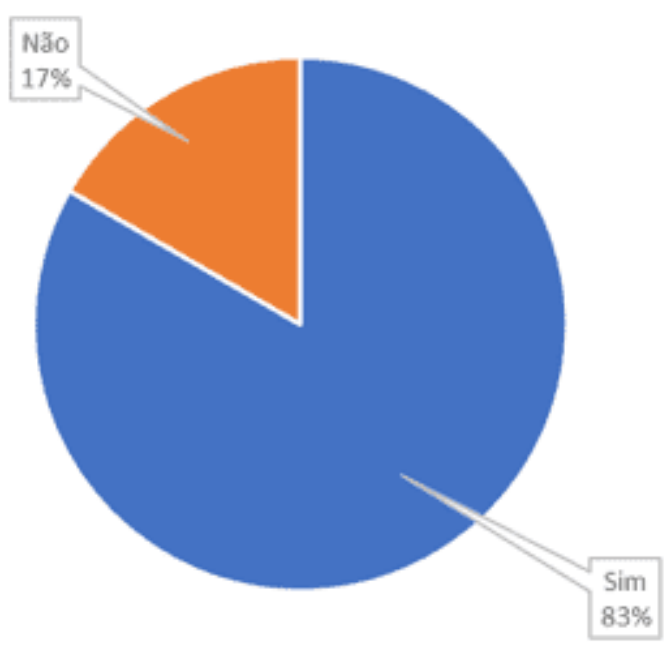

Fonte: autores.

$\mathrm{RC}: 106346$

Disponível em: https://www.nucleodoconhecimento.com.br/saude/processo-alimentar 
Gráfico 7. P 4.2. Por quanto tempo você pode amamentar?

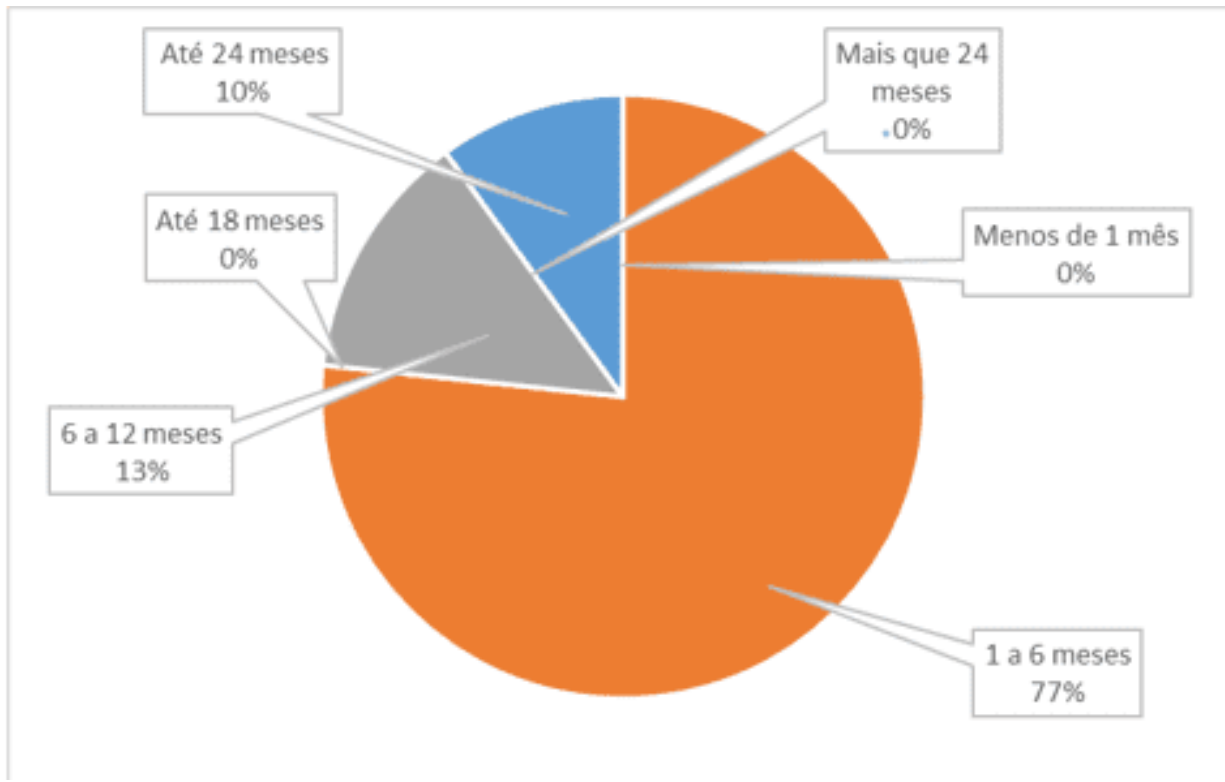

Fonte: autores.

Gráfico 8. P 5. Quais foram as sensações enquanto você amamentava seu bebê?

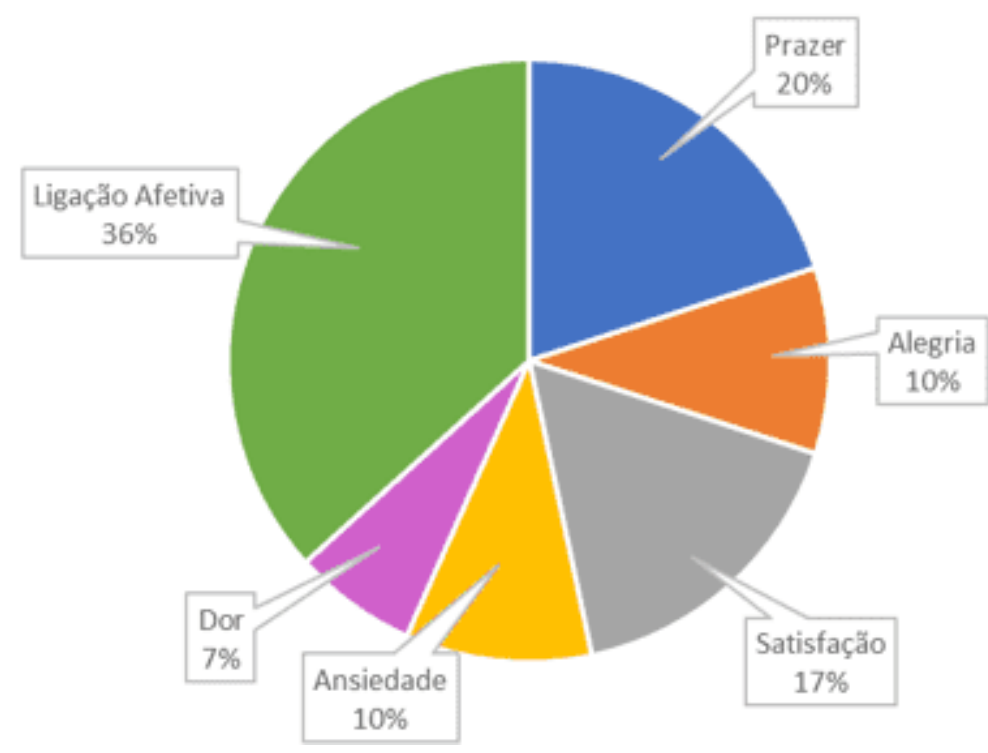

Fonte: autores.

RC: 106346

Disponível em: https://www.nucleodoconhecimento.com.br/saude/processo-alimentar 
Gráfico 9. P 6 . O bebê mamava bem?

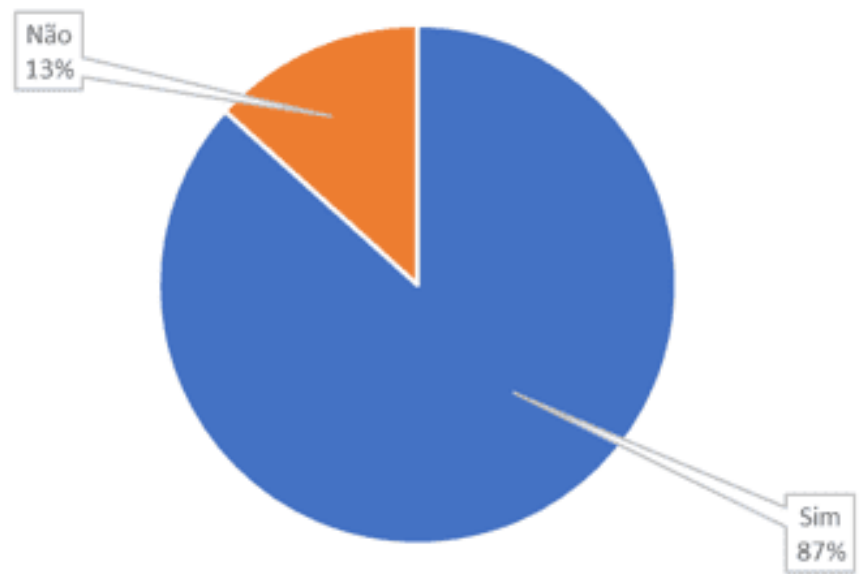

Fonte: autores.

Gráfico 10. P 7.1. Você interagia com seu bebê durante a amamentação?

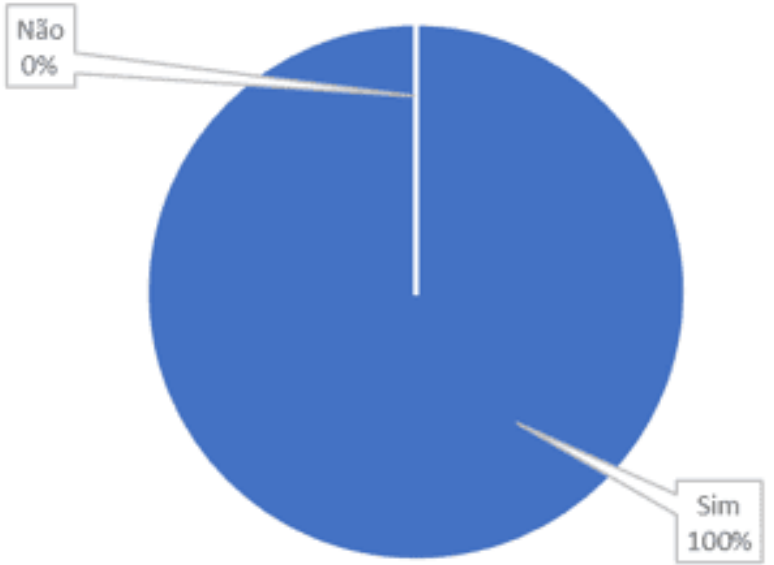

Fonte: autores.

RC: 106346

Disponível em: https://www.nucleodoconhecimento.com.br/saude/processo-alimentar 
Gráfico 11. P 7.2. Como?

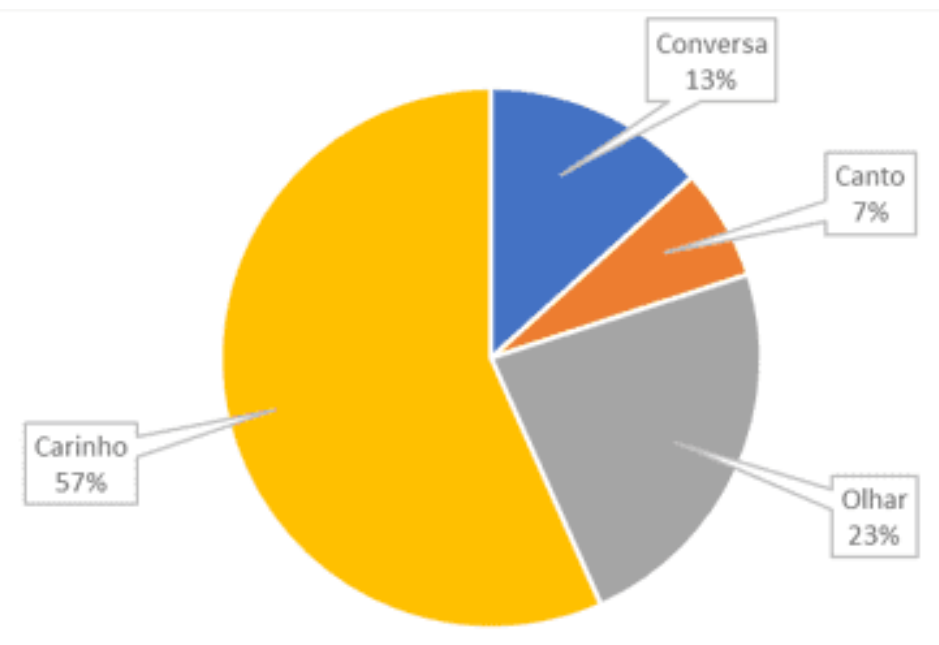

Fonte: autores.

Gráfico 11. P 8.1. O bebê reagia a essas interações?

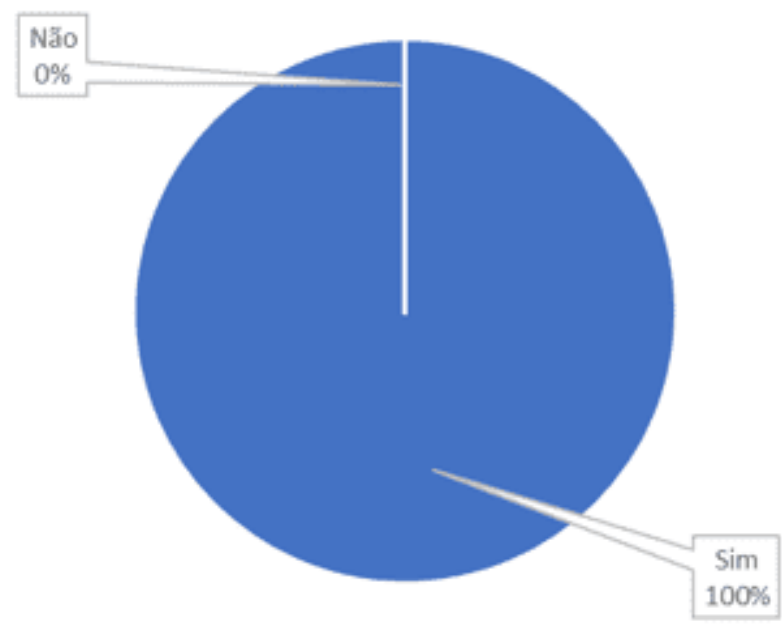

Fonte: autores.

RC: 106346

Disponível em: https://www.nucleodoconhecimento.com.br/saude/processo-alimentar 
Gráfico 12. P 8.2. O que o bebê fazia?

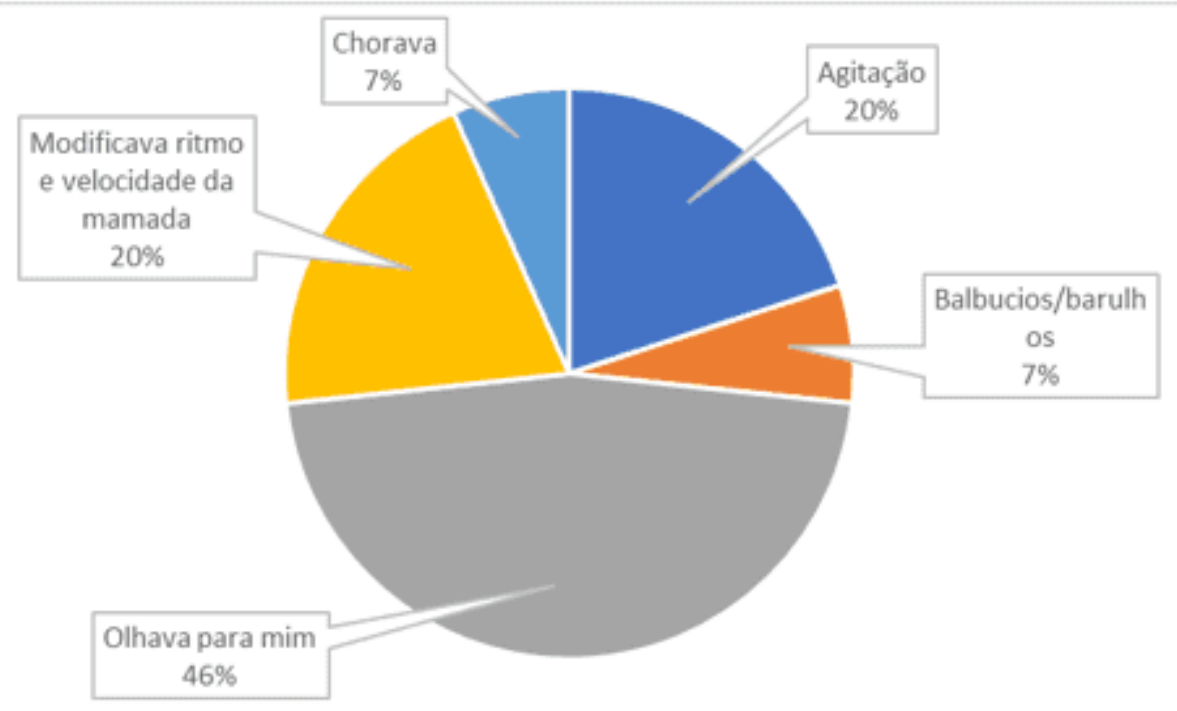

Fonte: autores.

Representações gráficas referentes ao Bloco 3 do instrumento "Desmame".

Gráfico 13. P 9. O desmame foi tranquilo?

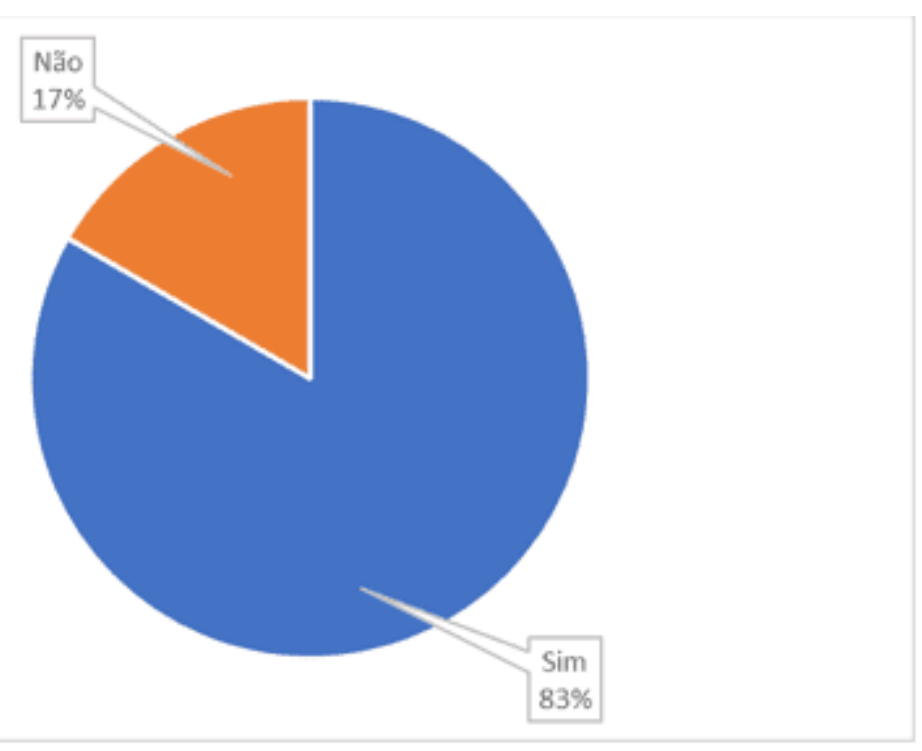

Fonte: autores.

RC: 106346

Disponível em: https://www.nucleodoconhecimento.com.br/saude/processo-alimentar 
Gráfico 14. P 10.1. Você recebeu orientações sobre o desmame?

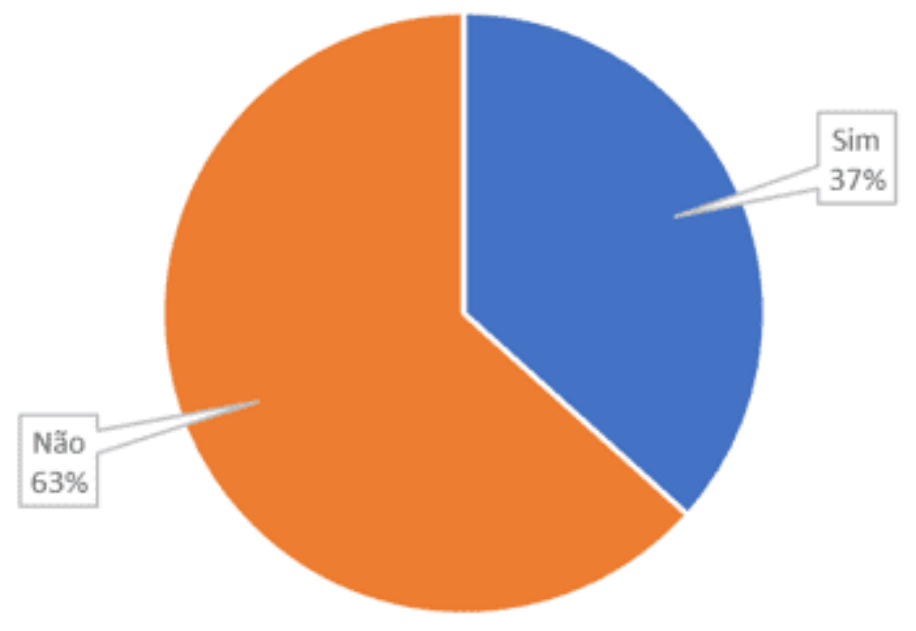

Fonte: autores.

Gráfico 15. P 11. Como aconteceu o desmame?

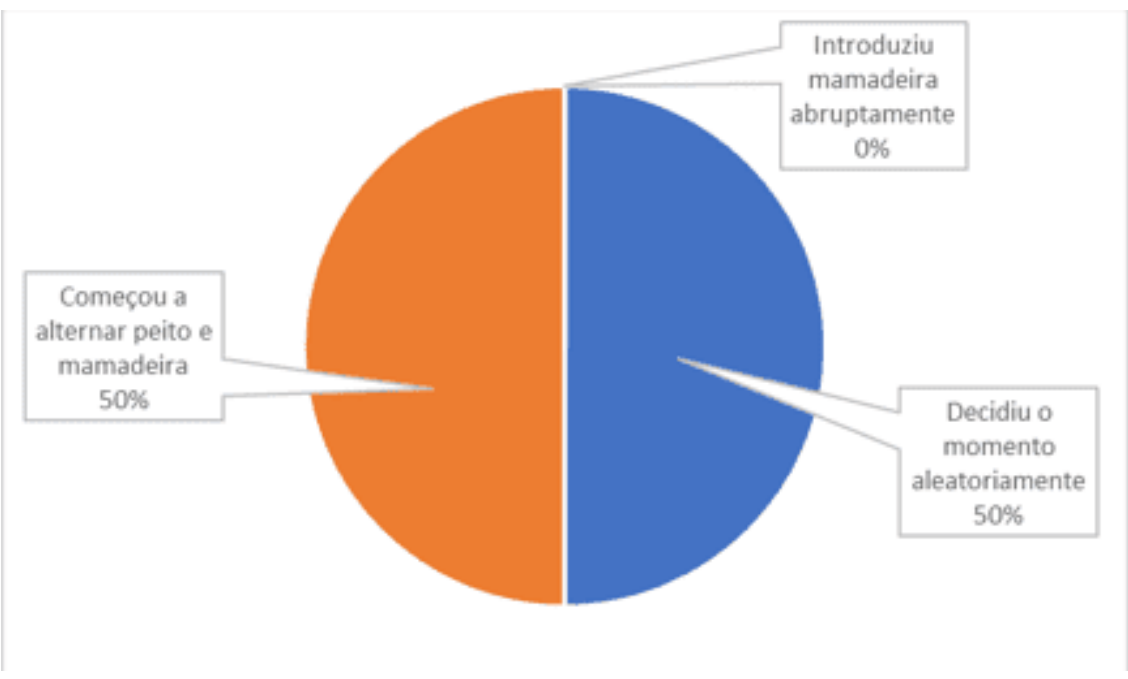

Fonte: autores.

RC: 106346

Disponível em: https://www.nucleodoconhecimento.com.br/saude/processo-alimentar 
Representações gráficas referente ao Bloco 4 "Introdução de alimentos".

Gráfico 16. P 12. Você gostou de oferecer outros alimentos para o bebê?

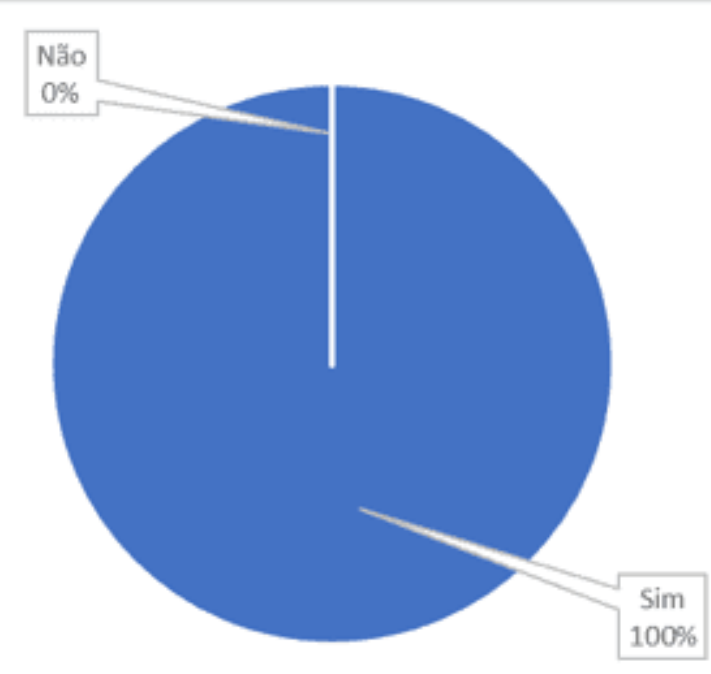

Fonte: autores.

Gráfico 17. P 13. A criança aceitou bem os alimentos oferecidos?

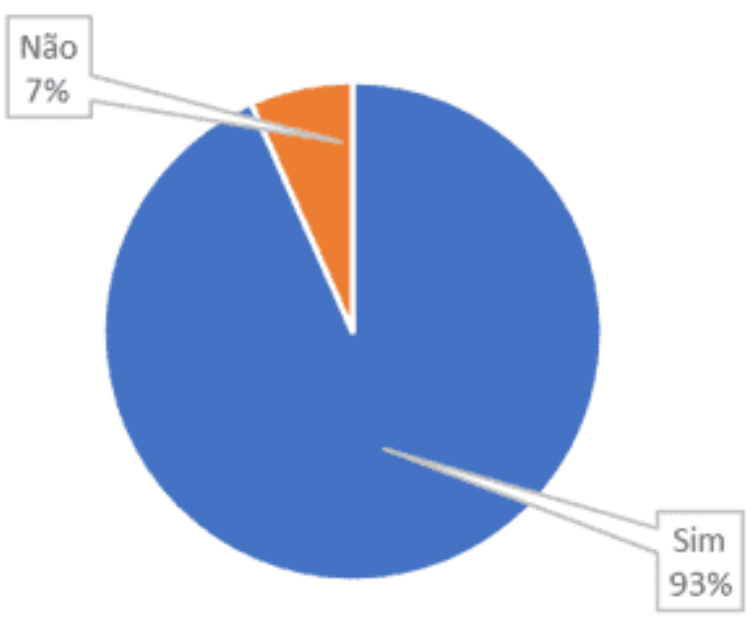

Fonte: autores.

RC: 106346

Disponível em: https://www.nucleodoconhecimento.com.br/saude/processo-alimentar 
Gráfico 18. P 14. Você gosta(va) de alimentar a criança?

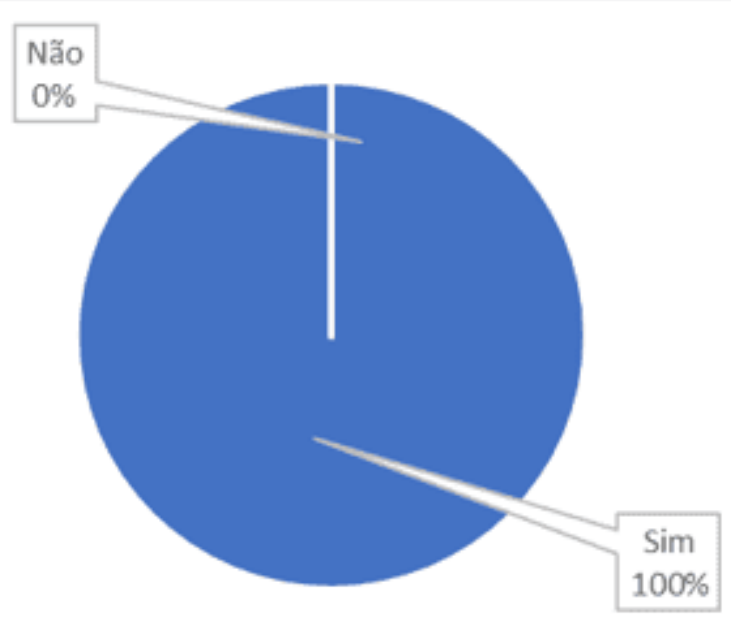

Fonte: autores.

Gráfico 19. P 15. Onde você alimenta(va) a criança?

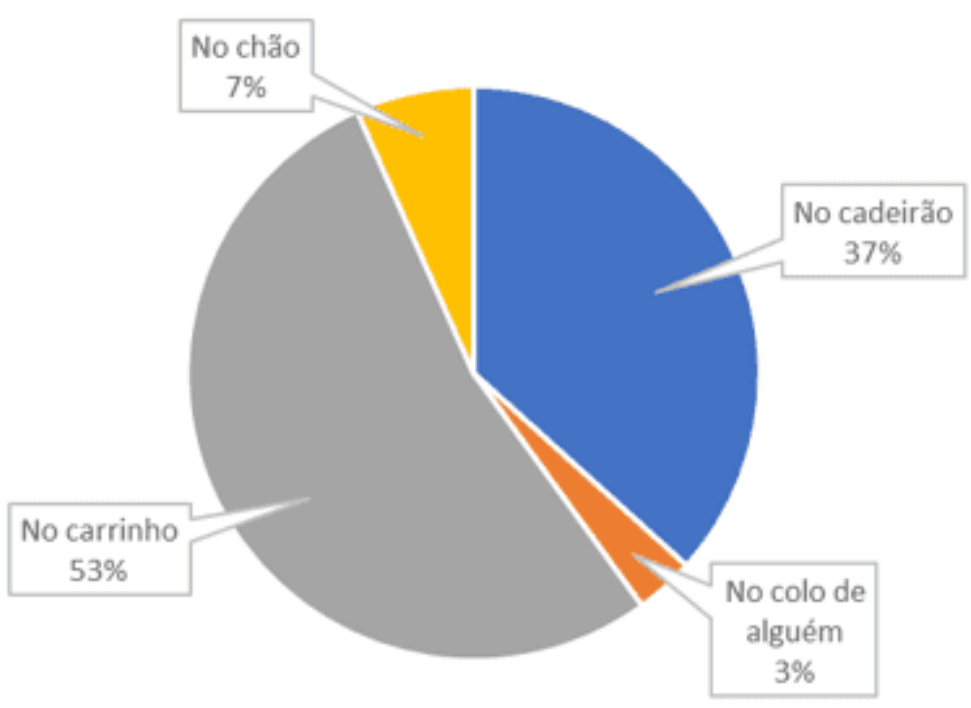

Fonte: autores.

RC: 106346

Disponível em: https://www.nucleodoconhecimento.com.br/saude/processo-alimentar 
Gráfico 20. P 16. Como você interage(ia) com a criança durante a alimentação?

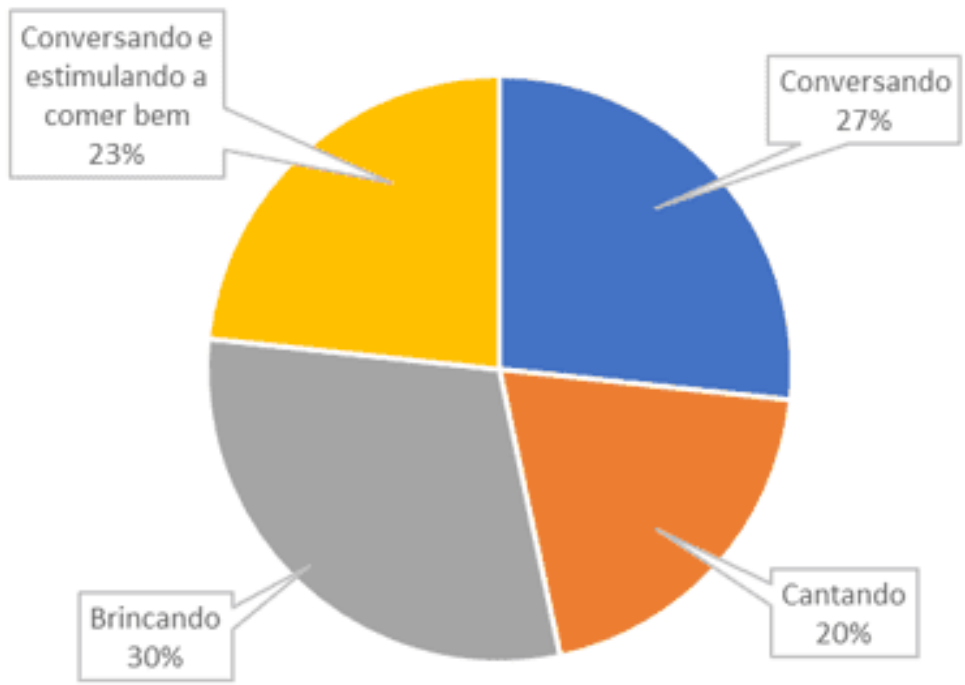

Fonte: autores.

Gráfico 21. P 17. Quando a criança começou a comer sozinha?

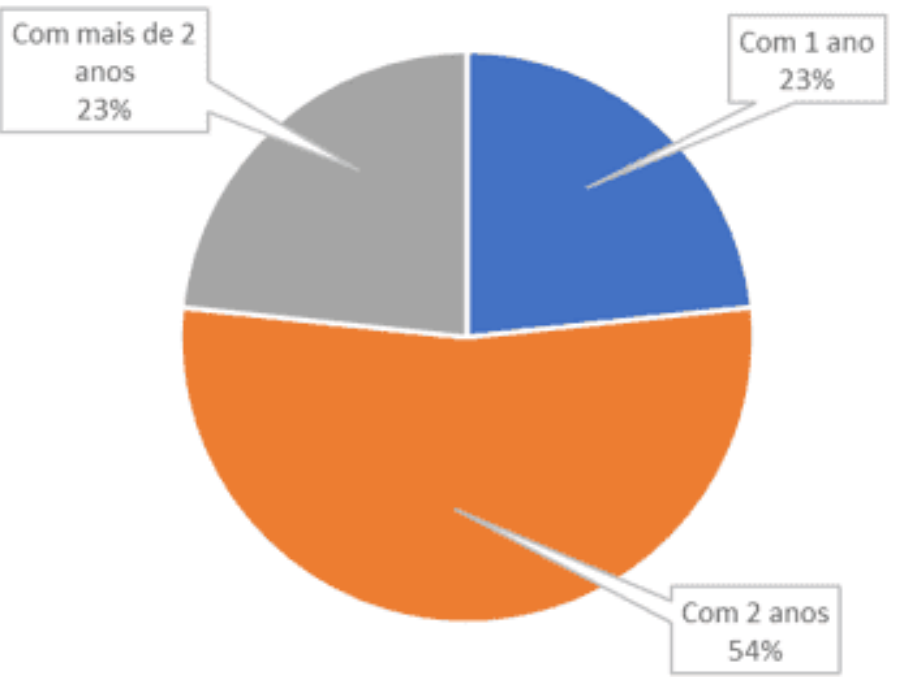

Fonte: autores.

RC: 106346

Disponível em: https://www.nucleodoconhecimento.com.br/saude/processo-alimentar 
Gráfico 22. P 18. Quando a criança começou a participar das refeições familiares?

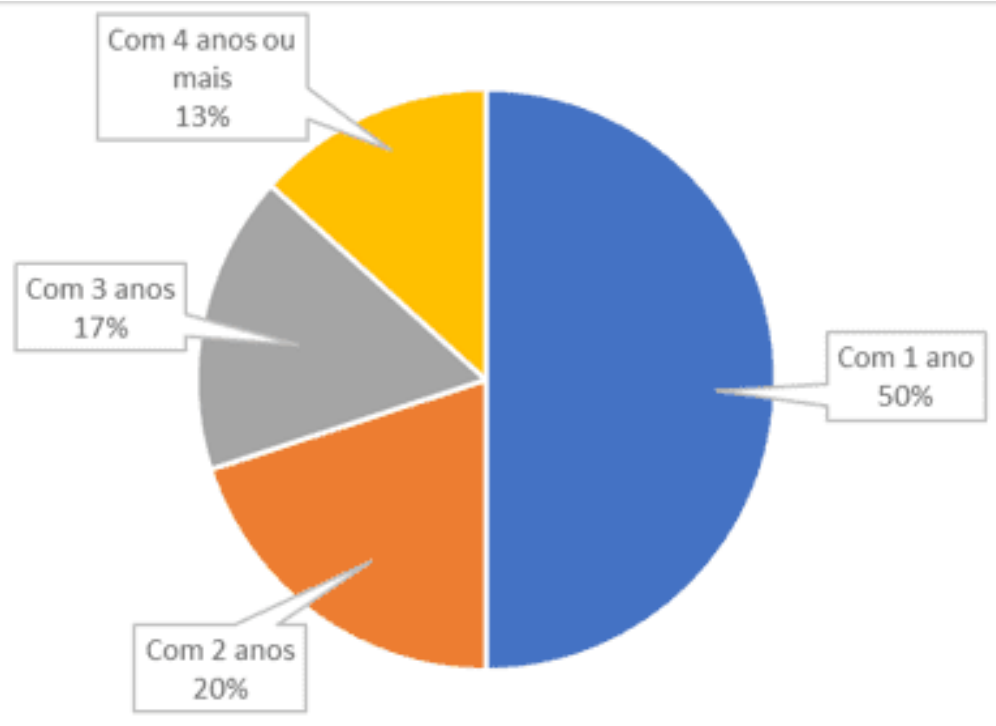

Fonte: autores.

Gráfico 23. P 19. Você conversa(va) sobre o gosto dos alimentos?

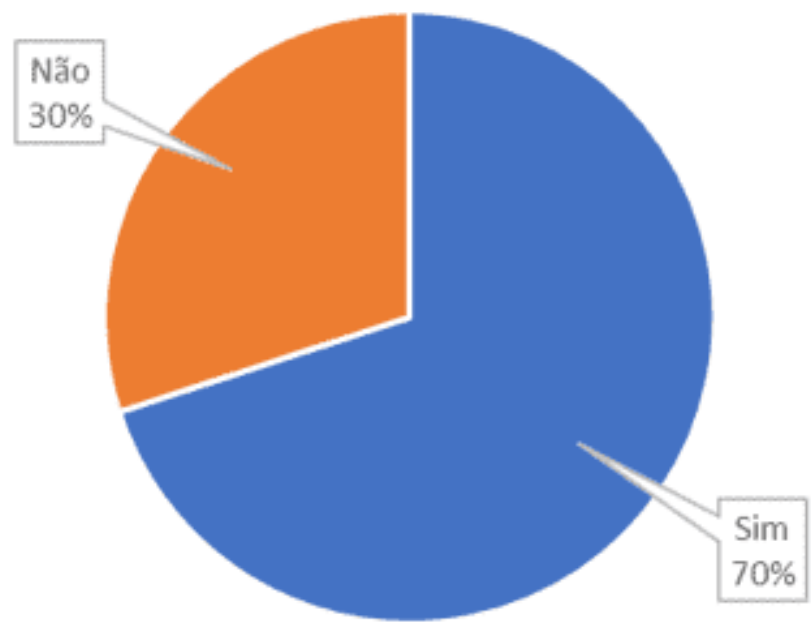

Fonte: autores.

RC: 106346

Disponível em: https://www.nucleodoconhecimento.com.br/saude/processo-alimentar 
Gráfico 24. P 20. Você respeita(va) o gosto da criança na preparação das refeições?

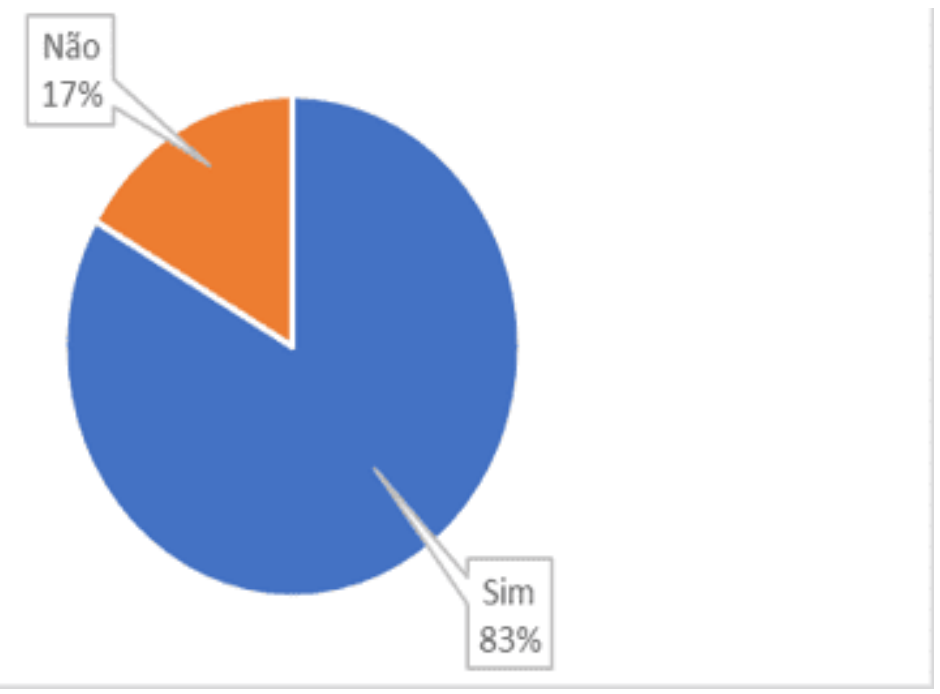

Fonte: autores.

\section{DISCUSSÃO}

Os dados mostram que a amamentação é um projeto ansiado pelas mães (P 1.1), visando a saúde do bebê ( $P$ 1.2). Tal projeto é, também, incentivado ( $P$ 1.2) por enfermeiras, pediatras, obstetras ( $P$ 2.2) (o que pode revelar o fato da orientação ocorrer, sobretudo, em fase pós-parto), acompanhando os mesmos apontamentos de muitas pesquisas sobre a formação do projeto de maternidade que, tradicionalmente, tem realce na nutrição do bebê (FREIRE, 2008; GUEDES e DAROS, 2009), dado que indicações alimentares são o forte do aconselhamento, ao lado daquelas sobre melhor posicionamento do bebê para adequada apreensão do bico do seio da mãe e consequente adequada sucção, aspecto importante para a garantia de uma boa alimentação ( $P$ 3). Para $P$ 3. há algumas respostas ligadas à importância da amamentação para a construção do vínculo entre mãe e bebê (CRESTANI, 2012; ALVARENGA et al., 2015), mas não configura maioria. Fica evidente que há tendência de se operar uma orientação sobretudo nutricional na questão da amamentação, com clara adoção da ideia pelas mães que, interessantemente, em outra pergunta (P 5), apontam que $\mathrm{o}$ ato de amamentar constituiu para elas momentos de prazer e alegria pessoal, além de ser uma cena de interação e de ligação afetiva. Esses aspectos, tão discretos nas orientações, surgem vigorosos nas palavras das mães. Lugar de RC: 106346

Disponível em: https://www.nucleodoconhecimento.com.br/saude/processo-alimentar 
narcisismo, pois trata-se de oferecer ao bebê "a primeira ingestão da vida no colo da onipresença materna" (LAJONQUIĖRE, 2010, p. 152), um privilégio, instância de grande potência, instância em que a mãe desempenha a "função do próximoassegurador, através dos cuidados indispensáveis à sobrevida, não somente a satisfação das necessidades, mas, também e sobretudo, a emergência psíquica do bebê" (CABASSU, 2003, p. 23).

Em outras palavras, a cultura eleva a mãe em sua posição de alimentadora cuidadosa e responsável pela saúde da criança, mas opaciza suas contingências psíquicas nas considerações, tais como o prazer desta posição. Nota-se que P.5 é um questionamento qualitativo, aberto à diversidade, mas exatamente pela gama extensa de respostas concernentes a estados psicológicos diversos, denotando grande singularidade na percepção da situação de amamentação, em termos de sensações e sentimentos, as mães mostram aspectos importantes na posição de alimentadora. Inclusive há apontamentos de desconforto e dor, situações atípicas e não previstas para situação tão revigorante - como referendado pela cultura -, o que reforça o caráter individual que configura tal posição.

Importa, assim, considerar a possibilidade de uma mulher preferir não amamentar ou não desfrutar de sensações agradáveis na amamentação, quer dizer, importa não romantizar esse ato, não expondo as mães a uma situação de vulnerabilidade, por exemplo, na aplicação de programas institucionais que se voltam radicalmente para a amamentação (LIMA e SOUZA, 2013). Szejer (2016, pp. 49 e 50, parênteses nossos) alerta que "a palavra de ordem geral das maternidades agora é: amamentem senhoras! Amamentem! Esta pressão tende talvez a restabelecer a situação natural que diz que a mãe, enquanto mamífero, tem esse desejo (...)" contudo, a autora segue argumentando, o ser humano é falante, diferente dos (outros) mamíferos e isso muda tudo. O que pode ser violento é, certamente, um apoio falho ou de má qualidade, são também todos os aleitamentos bem-sucedidos ou falhos, que povoam a história das famílias maternas e paternas e que podem vir a perturbar, de diversas maneiras, através da alimentação, as primeiras relações mãe-bebê. 
Outro fato que vale considerar é a mudança no corpo da mulher, na gestação e agora na amamentação, concernente ao inchaço das mamas, produção de leite, postura de amamentação, dor no processo, desconforto etc., que atravessa sua relação com o bebê, uma vez que a mãe está também capturada por esse novo corpo sobre o qual, além de tudo, ela tem dificuldade em controlar (CARREIRO et al., 2018) e, talvez, gostar. Porém, o que reverbera na mãe - as modificações de seu corpo e novas exigências - não ganha espaço nas reflexões, com considerações distantes de seus sentimentos e sensações e próximas de sua faixa etária, condição profissional, grau de escolaridade etc. (BARBOSA et al., 2017). São traços de identificação social que parecem compor, tradicionalmente, o interesse maior da discussão.

No estudo, verificou-se que a amamentação é prolongada, indo, na maior parte dos casos, do nascimento até os 06 meses do bebê ( $P 4.1$ e P 4.2), com relatos de sensações e sentimentos positivos: ligação afetiva, prazer e satisfação ( $P$ 5). Interessantes esses achados, pois, apesar de justificarem a amamentação no sentido da saúde do bebê, não escondem o prazer do ato e a satisfação narcísica de sua realização, além de reconhecerem sua potência afetiva. Isso explica que o êxito da amamentação depende de diversos fatores, como autoestima da mãe, intimidade com seu corpo, apoio familiar, assistência técnica (GALVÃO, 2006).

As mães confirmam que os bebês, em sua maioria, mamam bem ( $P$ 6), poucas fazem apontamentos sobre uma mamar mal de seus filhos ( $P$ 6), bem como algumas delas relatam sentimentos de desconforto, dor e ansiedade ( $P$ 5), o que se passa com muitas mães e que pode gerar desconforto, pois não correspondem ao ideal cultural. A questão do corpo surge novamente. Mais recentemente, estudos têm alertado para a necessidade de humanização do período de procriação - gestação, parto, puerpério -, visando compreender melhor a questão do corpo da mulher nesse processo, com menos sentidos culturais apriorísticos e mais conotações simbólicas (RUSSO e NUCCI, 2020)

As mães também indicam que a amamentação era momento de interação com o bebê (P 7.1), por meio da fala, do olhar e dos gestos de carinho (P 7.2), e das reações do bebê (P 8.1), sobretudo pelo olhar e alteração no ritmo da mamada ( $\mathrm{P}$ 8.2), o que 
caracteriza uma cena de plena intersubjetividade (GÓMEZ, 2014). Note-se como faz marca as reações positivas do bebê frente às condutas da mãe na amamentação.

O desmame também encena fatos interessantes: as mães, em sua maioria, relatam tranquilidade no processo (P 9), operado por volta dos 06 meses de idade do bebê, indicando, contudo, (mais que a metade delas), que não receberam orientação especializada e decidiram aleatoriamente o período da ruptura (P 10.1 e 10.2, P 11), afirmando que tiveram prazer na transição alimentar (P 12). Esta observação importa, pois, estudos mostram que pouca disponibilidade ou negatividade parental (nas transições) podem conduzir as crianças a problemas alimentares (HUÇALO e IVATIUK, 2017).

Assim como indicam positividade no processo de desmame, indicam bom aceite por parte dos bebês com a modificação alimentar ( $P$ 13); também indicam prazer no desenvolvimento da nova cena alimentar (P 14) (ÁVILA et al., 2007) com o bebê já em assento próprio e adequado (carrinho, cadeirão): retrato efetivo da constituição da subjetividade, com cenas de separação mãe-bebê, a começar pelo enquadre da alimentação (P 15). A alimentação se configura plenamente como cena de interação, com muita participação da mãe ( $\mathrm{P} 16$ ), até, aproximadamente, os dois anos da criança, quando a maioria começa a se alimentar sozinha $(P 17)$ e já participa das refeições familiares $(P$ 18), caracterizando a contingência de comensalidade dos humanos desde cedo (MOREIRA, 2010).

Interessante apontar que as mães informam o trabalho com a construção do gosto pelos alimentos e o respeito pelas preferências das crianças (P 19 e P 20), já com reconhecimento das crianças na posição de sujeito. Ao nascimento, os bebês parecem apontar preferências que remetem mais a um impulso biológico e, aos poucos, há modificações resultantes da estimulação exógena, principalmente da oferta materna (VENTURA e WOROBEY, 2013), e os dados mostram que as mães participam ativamente dessa construção. 


\section{CONCLUSÃO}

Os dados deste estudo mostram que a amamentação é um desejo das mulheres, o que põe em realce o vigor e o valor dessa sua posição, a de alimentadora e, mais ainda, de ser fonte do alimento.

Por outro lado, verifica-se que a orientação especializada para as mulheres sobre a amamentação é feita, sobretudo, em período pós-natal, privilegiando sua importância quanto aos aspectos nutricionais da criança, como a literatura costuma apontar. Contudo, é possível verificar, em muitas respostas apresentadas pelas mães, que a amamentação constitui, principalmente, momento de prazer relacional, encenado pela intensa busca de interação com a criança, que reage com mudanças visíveis em seu comportamento corporal e, principalmente, porque olha para a mãe como resposta às suas palavras e carinhos. Quer dizer, as mães supõem ali intenção e comunicação.

Estudos mostram que se a amamentação não for com palavras e afeto, sua potência se esvai apesar da adequação do encaixe anatômico de um corpo ao outro e da fartura de alimento.

Os momentos de alimentação, pelas respostas apresentadas, compõem continuamente vivências prazerosas por parte da mãe, denotando o componente narcísico representado nas atitudes de alimentação: a primeira oferta, a de alimentos diferentes, o traçamento do paladar, o reconhecimento de preferências, o compromisso com o preparo da refeição da criança e, principalmente, com a garantia de seu lugar nas refeições familiares.

Pesquisas visando descrever e analisar o lado materno da díade mãe-bebê são importantes porque podem esclarecer a delicada dinâmica dessa relação e vislumbrar suas repercussões em todos os níveis da constituição humana. Portanto, estudos sobre o tema são fundamentais, auxiliando sobretudo os clínicos da infância, na sua difícil tarefa de tentar compreender as manifestações das crianças, quer elas representem seu crescimento, quer elas representem impasses e riscos em sua constituição. 


\section{REFERÊNCIAS}

ALVARENGA, P.; TEIXEIRA, J. N.; PEIXOTO, A. C. Apego materno-fetal e a percepção materna acerca da capacidade interativa do bebê no primeiro mês. Psico, v. 46 , n. 3, p. 340-50, 2015. Disponível em: https://doi.org/10.15448/19808623.2015.3.18657

ÁVILA, A. C. L; WEISS, F. B.; LAURINDO, M. C. Relação mãe-bebê e seus reflexos na questão da alimentação na primeira infância. Akrópolis umuarama, v. 15, n. 3, p. 159-63, 2007. DOI: https://doi.org/10.25110/akropolis.v15i3.1940

BAIÃO, M. R.; DESLANDES, S. F. Alimentação na gestação e puerpério. Rev Nutr, v. 19, n. 2, p. 245-53, 2006. DOI: https://doi.org/10.1590/S1415-52732006000200011

BARBOSA, G. E. F. et al. Dificuldades iniciais com a técnica da amamentação e fatores associados a problemas com a mama em puérperas. Revista Paulista de Pediatria [online]. v. 35, n. 3, p. 265-272, 2017. Disponível em: <https://doi.org/10.1590/1984-0462/;2017;35;3;00004>. Epub 13 Jul 2017. ISSN 1984-0462. https://doi.org/10.1590/1984-0462/;2017;35;3;00004.

CABASSU, G. Palavras em torno do berço: intervenções precoces: bebê e família. In: Wanderley, D. B. (org.), Bahia: Álgama, 2003.

CARREIRO, J. A.; FRANCISCO, A. A.; FREITAS DE VILHENA, A. C.; MARCACINE, K. O.; ABUCHAIM, E. S. V.; COCA, K. P. Dificuldades relacionadas ao aleitamento materno: análise de um serviço especializado em amamentação. ACTA Paul Enferm, v. 31, n. 4, p. 430-8, 2018. DOI: https://doi.org/10.1590/1982-0194201800060

CHATOOR, I.; HIRSCH, R.; GANIBAN, J.; PERSINGER, M.; HAMBURGUER, E. Diagnosing infantile anorexia: the observation of mother-infant interaction. Journal of the American Academy of Child \& Adolescent Psichiatric, v. 39, n. 6, p. 743-51, 2000. DOI: https://doi.org/10.1097/00004583-199809000-00016

COHN, C. Antropologia da Criança. São Paulo: Jorge Zahar, 2005. 
CRESTANI, A. H.; ROSA, F. F. M; RAMOS DE SOUZA, A. P. A experiência da maternidade e a dialogia mãe-filho com distúrbio de linguagem. Rev. Cefac, v. 14, n. 2, p. 350-60, 2012. DOI: https://doi.org/10.1590/S1516-18462010005000105

CUNHA, E. C.; SIQUEIRA, C. S. H. Aleitamento Materno: Contribuições da Enfermagem. Ensaios Cienc., Cienc. Biol. Agrar. Saúde, v. 20, n. 2, p. 86-92, 2016. Disponível em: https://www.redalyc.org/articulo.oa?id=26046651005

FERRARI, A. G.; CHERER, E. Q.; PICCININI, C. A. Aspectos subjetivos da amamentação e desmame: evidências em três casos. Rev Psicologia: Teoria e Pesquisa, v. 33, 2017. DOI: https://doi.org/10.1590/0102.3772e33411

FERRIOLLI, B. H. V. M. Associações entre alterações de alimentação infantil e distúrbios de fala e linguagem. Revista CEFAC, v. 12, n. 6, p. 990-997, 2010. DOI: https://doi.org/10.1590/S1516-18462010005000037

FOUCAULT, M. O nascimento da clínica. Rio de Janeiro: Forense Universitária, 1994.

FREIRE, M. M. L. 'Ser mãe é uma ciência': mulheres, médicos e a construção da maternidade científica na década de 1920. Revista História, Ciências, Saúde. Rio de Janeiro/Manguinhos, v. 15, p. 153-71, 2008. Suplemento. DOI: https://doi.org/10.1590/S0104-59702008000500008

FREUD, S. Três ensaios sobre a teoria da sexualidade (1905). ESB VII, Rio de Janeiro: Imago, 1996.

GALVÃO, D. M. P. G. Amamentação bem-sucedida: alguns factores determinantes. Revista de enfermagem Referência, v. 2, n. 2, p. 96, 2006. Disponível em: https://www.redalyc.org/articulo.oa?id=388242124003

GAMA, S. G. N.; VIELLAS, E. F.; SCHILITZ, A. O. C.; THEME FILHA, M. M.; LAZARO de CARVALHO, M.; GOMES, K. R. O.; COSTA, C. O. M.; LEAL, M. C. Fatores associados à cesariana entre primíparas adolescentes no Brasil, 2011-2012. 
Cadernos de Saúde Pública, v. 30, p. S117-S127, ago. 2014. DOI: https://doi.org/10.1590/0102-311X00145513

GIACCHINI, V.; TONIAL, A.; MOTA, H. B. Aspectos de linguagem e motricidade oral observados em crianças atendidas em um setor de estimulação precoce. Distúrb. Comum, São Paulo, v. 25, n. 2, p. 253-265, 2013.

GÓMEZ, M. A. Intersubjetividade nos primórdios da relação mãe-bebê. Dissertação (Mestrado em psicologia Clínica) - Pontifícia Universidade do Rio de Janeiro - PUC/RJ, 2014

GRISCI, C. L. I. Mulher-mãe. Rev Psicol. Cienc. Prof., v. 15, n. 1-3, p. 12-17, 1995. DOI: https://doi.org/10.1590/S1414-98931995000100003

GUEDES, O. S.; DAROS, M. A. O cuidado como atribuição feminina: contribuições para um debate ético. Serv. Soc. Rev, v. 12, n. 1, p. 122-134, 2009. DOI: 10.5433/1679-4842.2009v12n1p122

GUSMÃO, M. H. Os transtornos e as dificuldades da alimentação. Revista Latinoamericana de Psicopatologia Fundamental, v. 5, n. 1, p. 44-60, 2002. DOI: https://doi.org/10.1590/1415-47142002001005

HUÇALO, A. P.; IATIUK, A. L. A relação entre práticas parentais e o comportamento alimentar em crianças. Pluralidades em Saúde Mental, Curitiba, v. 6, n. 2, p. 113128, jul./dez. 2017.

JERUSALINSKY, A. Psicanálise e desenvolvimento infantil. 3" Edição. Porto Alegre: Ed Artes e Ofícios, 2004.

KREISLER, L. As condutas alimentares desviantes de alto risco do bebê. In: LEITGELGILLE, M. (org). Boi da Cara Preta. Crianças no hospital. Ed. Ágalma: BA, 2003, p. 118. 
KUPFER, M. C. Educação para o Futuro: psicanálise e educação. São Paulo: Escuta, 2000, p. 89.

LAJONQUIÈRE, L. De cozinheiro e de louco todo mundo tem um pouco. In: Kupfer, M. C. M e Pinto, F. S. C. N. (orgs). Lugar de vida, vinte anos depois. São Paulo: Ed. Escuta, 2010.

LIMA, L. S.; SOUZA, S. N. D. Percepção materna sobre apoio recebido para a amamentação: o olhar na perspectiva da vulnerabilidade programática. Semina: Ciências Biológicas e da Saúde, v. 34, n. 1, p. 73-90, 2013. DOI: http://dx.doi.org/10.5433/1679-0367.2013v34n1p73

LÉVI-STRAUSS, C. 0 cru e o cozido. Mitológicas 1- São Paulo: Cosac-Naify, p. 442, 2004.

MACHADO, F. P. Problemas de linguagem oral e de alimentação: coocorrências na clínica fonoaudiológica. 2007. Dissertação (Mestrado em Fonoaudiologia) Pontifícia Universidade Católica de São Paulo - PUC/SP, São Paulo, 2007.

MARTINS, A. P. V. "Vamos criar seu filho": os médicos puericultores e a pedagogia materna no século XX. História, Ciências, Saúde-Manguinhos [online], v. 15, n. 1, 2008. DOI: https://doi.org/10.1590/S0104-59702008000100008.

MARIOTTO, R. M. M. Distúrbios alimentares em bebês: uma interlocução entre a fonoaudiologia e a psicanálise. R. Dist. Comun., São Paulo, v. 14, n. 2, p. 263-274, jun. 2003.

MONTANARI, M.; FLANDRIN, J. L. História da alimentação. São Paulo, Ed. Estação Liberdade, 2003

MOREIRA, S. A. Alimentação e comensalidade: aspectos históricos e antropológicos. Cien. Culto., São Paulo, v. 62, n. 4, p. 23-26,2010. Disponível em: <http://cienciaecultura.bvs.br/scielo.php?script=sci_arttext\&pid=S0009- 
$67252010000400009 \& \operatorname{lng}=e n \& n r m=i s o>$. Acesso em 29 de janeiro de 2022. Acesso 27 Dez. 2021.

PALLADINO, R. R. R.; SOUZA, L. A. P.; CUNHA, M. C. Transtornos de linguagem e transtornos alimentares em crianças. Psicanál. univ, Campinas, v. 21, p. 95-108, set. 2004.

PALLADINO, R. R. R.; CUNHA, M. C; SOUZA, L. A. P. Problemas de linguagem e alimentares em crianças: coocorrências ou coincidências?. Pró-Fono Revista de Atualização Científica [online], v. 19, n. 2, p. 205-214, Jun. 2007. Disponível em: $<$ https://doi.org/10.1590/S0104-56872007000200009>. Epub 16 Set 2008. ISSN 0104-5687. DOI: https://doi.org/10.1590/S0104-56872007000200009.

PALLADINO, R. R. R; SOUZA, L. A. P.; PALLOTTA, M. L.; COSTA, R.; CUNHA, M. C. Dormir, comer e falar: enlaçamento simbólico. Revista Científica Multidisciplinar Núcleo do Conhecimento, São Paulo, v. 6, n. 8, p. 153-170, 2021. DOI:10.32749/nucleodoconhecimento.com.br/psicologia/enlacamento-simbolico

PEDROBOM, R. B.; MACHADO, F. P.; CUNHA, M. C; PALLADINO, R. R. R. A oficina de cozinha como dispositivo terapêutico fonoaudiológico. Rev. Distúrb. Com.; São Paulo, v. 21, n. 1, p. 15-20, 2009. Disponível em: https://revistas.pucsp.br/index.php/dic/issue/view/471

PEDROBOM, R. B. Problemas de linguagem e de alimentação: manifestações da fixação oral na clínica fonoaudiológica. Tese (Doutorado em Fonoaudiologia), Pontifícia Universidade Católica de São Paulo, São Paulo, 2012.

PRADO, S. D.; VARGAS, E. P.; CARVALHO, M. C. V. S.; FERREIRA, M. C.; ROMÃO, F.; SEIXAS, M. C.; KRAEMER, F. B. Relações entre alimentação, obesidade, perda de peso e consumo em revistas femininas. Demetra: Alimentação, Nutrição \& Saúde, v. 11, 2017. DOI: 10.12957/demetra.2016.26514 
QUINIOU, Y. Alimentar, ser alimentado em UTI neonatal- prescrição ou alimentação? In: Wanderley, D. B. (org) Agora eu era o rei. Os entraves da prematuridade. Bahia: Ed. Ágalma, 1999.

REGA, A. I. O comportamento alimentar e o desenvolvimento de linguagem em crianças nascidas pré-termo. Tese (doutorado em Psicologia) - Faculdade de Psicologia, Universidade de Lisboa, 2018.

ROCHA, A. M. Comida e a linguagem em "Folclore da alimentação" (1963): Cascudo, os folcloristas e a cultura alimentar. Revista Práksis, v. 1, 2018, pp 64-80. DOI: https://doi.org/10.25112/rpr.v1i0.1465

RUSSO, J. A.; NUCCI, M. F. Parindo no paraíso: parto humanizado, ocitocina e a produção corporal de uma nova maternidade. Interface - Comunicação, Saúde, Educação [online], v. 24, 2020. Disponível em: <https://doi.org/10.1590/Interface.180390>. Epub 17 Jan 2020. ISSN 1807-5762. DOI: https://doi.org/10.1590/Interface.180390.

SEABRA, G.; PADILHA, P. C.; SAUNDERS, C. Sobrepeso e obesidade prégestacionais: prevalência e desfechos associados à gestação. Revista Brasileira de Ginecologia e Obstetrícia [online], v. 33, n. 11, p. 348-353, 2011. DOI: https://doi.org/10.1590/S0100-72032011001100005

SILVA GOMES, V. T.; GOMES, R. N. S.; GOMES, M. S.; VIANA, L. V. M.; DA CONCEIÇÃO, F. R.; DE AMORIM, L. M. M.; GENARO, P. de S. Nutrição e autismo: reflexões sobre a alimentação do autista. Revista Univap, v. 22, n. 40, p. 656, 2017. DOI: 10.18066/revistaunivap.v22i40.1298.

SOUZA LIMA, R.; FERREIRA NETO, J. A.; FARIAS, R. C. P. Alimentação, comida e cultura: o exercício da comensalidade. Revista Demetra, v. 10, n. 3, p. 507-22, 2015. DOI: $10.12957 /$ demetra.2015.16072

SZEJER, M. Se os bebês falassem. São Paulo: Instituto Language, 2016. 
THIBAULT, C. A língua, órgão chave das oralidades. Rééduc. orthophon., Paris, ano 42, n. 226, p. 115-124, jun. 2006.

VENTURA, A. K.; WOROBEY, J. Early influences on the development of food preferences. Curr Biol., v. 23, n. 9. p. 401-8, 2013. DOI: https://doi.org/10.1016/j.cub.2013.02.037

Enviado: Fevereiro, 2022.

Aprovado: Fevereiro, 2022. 